\title{
Subcomplexo regional de segurança do Golfo Pérsico: uma mudança de polaridade?
}

Persian Gulf Regional Security: a change in polarity?

\author{
Murillo Silva de Lima ${ }^{1}$
}

\section{RESUMO}

Por meio da teoria dos complexos regionais de segurança (TCRS), propõe-se uma atualização da análise do subcomplexo regional de segurança do Golfo Pérsico. Lança-se a hipótese de que há uma mudança de polaridade no interior do subcomplexo de triangular para bipolar. Conclui-se que Irã e Arábia Saudita balanceiam um ao outro, enquanto o Iraque perdeu o status de potência regional.

Palavras-chave: teoria dos complexos regionais de segurança; Golfo Pérsico; polaridade.

\begin{abstract}
Through regional security complexes theory (RSCT) it proposes an update of the analysis of the Gulf subcomplex. It suggests the hypothesis that there is a change of polarity inside the subcomplex from a triangular to a bipolar one. It is concluded that Iran and Saudi Arabia balance each other while Iraq has lost the status of a regional power.
\end{abstract}

Keywords: Regional Security Complex Theory; Persian Gulf; Polarity.

\section{INTRODUÇÃo}

As contribuições da teoria dos complexos regionais de segurança (TCRS), desenvolvida por Buzan e Wæver (2003), dispõem de ferramentas significativas para os estudos dos fenômenos de segurança internacional. Na TCRS, o centro de análise passa para o regional, um meio-termo entre o sistema global e o Estado. Nesse sentido, Buzan e Wæver (2003), ao analisar os complexos regionais de segurança (CRS) ao redor do globo, notaram o complexo regional de segurança do Oriente Médio (CRSOM) subdividido em três subcomplexos: do Maghreb, do Levante e do Golfo Pérsico, sendo o CRSOM, como um todo, caracterizado pelo caráter permanentemente conflituoso.

\footnotetext{
1 Bacharel em Relações Internacionais (UFPel) e mestrando em Relações Internacionais (UFSC), Florianópolis, Brasil.

Conjuntura Global, vol. 5 n. 2, mai./ago., 2016, p. 304 - 318.
} 
O artigo busca, especificamente, atualizar as contribuições de Buzan e Wæver acerca do subcomplexo regional de segurança do Golfo Pérsico. Os autores demonstraram que a estrutura básica triangular (Arábia Saudita, Irã e Iraque) já apresentava sinais de mudanças estruturais e de seus componentes no período que sucedeu o fim da Guerra do Golfo (1990-1). Uma das principais consequências do conflito, segundo os autores, foi o enfraquecimento militar do Iraque em relação às duas potências vizinhas, o que mudou a distribuição de poder no subcomplexo, sem, todavia, alterar a estrutura básica triangular de rivalidade.

Tendo em vista essa tendência de mudança na polaridade do subcomplexo do Golfo apontada pelos próprios autores, o artigo buscará atualizar suas contribuições no período que se segue à invasão do Iraque liderada pelos Estados Unidos (2003) até maio de 2015. A invasão do Iraque é um evento com consequências que os autores não poderiam dimensionar devido à própria data de publicação da obra Regions and powers, no mesmo ano. Levando-se em consideração que os eventos analisados transcorrem até maio de 2015, não foram contemplados neste estudo as consequências da assinatura, em julho de 2015, do Acordo de Viena, sobre o projeto nuclear iraniano, bem como os desdobramentos importantes da guerra civil síria (2011) observados após a intervenção russa no país, iniciada em setembro de 2015.

Quanto à divisão do artigo, em primeiro lugar, será realizada uma breve revisão teórica baseada na obra de Buzan e Wæver (2003). Na seção seguinte será feita uma revisão da história do subcomplexo do Golfo com base na análise dos autores, em que será retomado o período desde a Guerra do Golfo (1990-1), quando a estrutura básica triangular começa a dar sinais de transformação, até 2003. A próxima seção passará para uma análise, à luz das ferramentas teóricas dos CRSs, das consequências da invasão ao Iraque em 2003, enquanto a seção seguinte abordará o surgimento e ascensão do Estado Islâmico. Ambos os eventos e seus desdobramentos são expostos como fatores que contribuíram para a perda de capacidades do Iraque e de seu status como potência regional. Tomando as raízes construtivistas da TCRS, em outra seção, serão tratadas as mudanças de padrões de amizade e inimizade entre as potências regionais do subcomplexo. Por fim, conclui-se que, com a perda, por parte do Iraque, do status de potência regional, a estrutura básica triangular de rivalidade tornou-se bipolar entre Irã e Conselho de Cooperação do Golfo (CCG) sob a liderança saudita. Além de uma 
redistribuição das capacidades entre as potências regionais, houve também alterações entre os padrões de amizade e inimizade no subcomplexo do Golfo.

\section{Revisão teórica}

A TCRS foi desenvolvida dentro da Escola de Copenhague. Pôs no centro de análise o nível regional, um meio-termo entre o global e o estatal. Segundo essa teoria, os CRSs são definidos como padrões duráveis de amizade ou inimizade que tomam uma forma subglobal, isto é, padrões geograficamente coerentes de interdependência no âmbito da segurança. Os CRSs são afetados por fatores históricos, tais como padrões de inimizade de longa data (árabes e persas, por exemplo) ou sentido de pertencimento a uma cultura comum (BUZAN; WÆVER, 2003). Buzan e Wæver definiram CRS como "um conjunto de unidades cujos principais processos de securitização, dessecuritização, ou ambos, são tão interligados que seus problemas de segurança não podem ser razoavelmente analisados ou resolvidos separados uns dos outros" (ibidem, p. 44, tradução nossa). Unidade é utilizada pelos autores como sinônimo de Estado. Afirmam que "é perfeitamente possível que o mundo ainda seja largamente estadocêntrico" (ibidem, p. 44, tradução nossa).

Buzan e Waever também trouxeram o conceito de subcomplexo, ao qual este artigo confere ênfase. Subcomplexo, um meio-termo dentro de um CRS, tem essencialmente a mesma definição de complexo. A diferença entre os dois é que o subcomplexo está firmemente incorporado a uma estrutura maior, um CRS (BUZAN; WAEVER, 2003). Subcomplexos representam distintivos padrões de interdependência nos temas de segurança que não são apanhados em um aspecto mais amplo que abarque o CRS como um todo.

Buzan e Wæver (2003) propuseram critérios para definição das unidades em três categorias: superpotência, grande potência e potência regional. Entre estes, o artigo atenta para a definição da categoria de potência regional, visto que as potências no CRSOM foram enquadradas pelos autores nessa categoria.

Potências regionais definem a polaridade de qualquer dado CRS: unipolar como na África Austral, bipolar como no Sul da Ásia, multipolar como no Oriente Médio, América do Sul e Sudeste Asiático. Suas capacidades restringem-se a suas regiões, mas não atingem um espectro mais amplo em nível global. Poderes de nível superior respondem a elas (potências regionais) como se sua 
influência e capacidade fossem principalmente relevantes para os processos de securitização de uma determinada região. Elas são, por outro lado, excluídas dos cálculos de nível mais alto de polaridade sistêmica [...]. Potências regionais podem, evidentemente, envolver-se em rivalidades de poder em nível mundial (ibidem, p. 37, grifo e tradução nossos).

Uma potência regional precisa ter influência e capacidades sobre os processos de securitização da região. Isso implica a possessão de capacidades políticas e militares, com suporte econômico para tais capacidades. Além dos fatores materiais, é preciso posicionar-se como potência regional, o que envolve comportamento (idem, 2003).

Como as potências regionais também atuam como definidoras da polaridade de um determinado CRS, estes são classificados em duas grandes tipologias: padrão e centralizado (idem, 2003). Para Buzan e Wæver (2003), o CRSOM, como um todo, é do tipo padrão multipolar, que, além das potências regionais do subcomplexo do Golfo envolve Egito e Israel, potências regionais do subcomplexo do Levante. Já o subcomplexo do Golfo, especificamente, está calcado em uma estrutura triangular de rivalidade entre Irã, Iraque e Estados árabes do Golfo Pérsico liderados pela Arábia Saudita (idem, 2003). Essa estrutura triangular já não se sustenta após os eventos que se seguiram à queda de Saddam Hussein, como sugere a hipótese levantada.

\section{História do subcomplexo regional do Golfo Pérsico (1971-2003)}

Segundo a definição de Buzan e Wæver (2003), o CRSOM compreende três subcomplexos que se estendem desde Marrocos até o Irã. O subcomplexo do Golfo é formado por Irã, Iraque, Iêmen e CCG; o subcomplexo do Levante, por Israel, Egito, Síria, Líbano e Jordânia; e o subcomplexo de Maghreb é constituído por Marrocos, Argélia, Tunísia e Líbia, enquanto o Afeganistão atua como um país isolador entre a Ásia do Sul e o CRSOM, e a Turquia, entre este e a Europa.

O subcomplexo do Golfo foi constituído após a saída da Grã-Bretanha da região, em 1971. Segundo Buzan e Wæver (2003), desde o princípio manifestou-se centrado na rivalidade triangular entre Irã, Iraque e Arábia Saudita. Esta, desde 1981, lidera o CCG formado por outras cinco monarquias: Bahrein, Kuait, Qatar, Emirados Árabes Unidos e Omã. Essa formação triangular conflituosa do subcomplexo tem sido direcionada por uma agenda tradicional de disputas territoriais, competição ideológica, rivalidades por poder e status, divisões étnicas e sectárias, bem como disputas sobre recursos derivados 
do petróleo (idem, 2003). Os eventos pós-Guerra Fria para o CRSOM são, em parte, consequências da diminuição do apoio aos clientes da União Soviética na região. Porém, isso não significou um decrescimento da intervenção de superpotências, mas uma mudança em direção à unipolaridade sistêmica da superpotência Estados Unidos, que passou a usar sua influência para mitigar dinâmicas conflitivas de segurança entre os Estados - porém, não intraestatais - dos dois subcomplexos principais: do Levante e do Golfo (idem, 2003).

Gause (2014) apresenta uma boa síntese desse quadro introdutório acerca do subcomplexo exposto por Buzan e Wæver (2003). Segundo o autor (2014, p. 1, tradução nossa), a rivalidade entre as potências regionais no subcomplexo do Golfo deve ser entendida pela análise das "conexões entre conflitos domésticos, afinidades transnacionais e Estados com ambições regionais". Nesse jogo, os poderes globais são participantes importantes, mas não os condutores dos eventos. 0 subcomplexo do Golfo e o CRSOM como um todo constituem uma região com grande autonomia nas dinâmicas de segurança, a despeito das contínuas imposições do nível global. Embora o Estado seja o quadro analítico principal no Oriente Médio, no nível doméstico, as entidades subestatais e grupos armados, além de desempenhar um papel significativo na produção das vulnerabilidades internas, também reverberam nas dinâmicas de segurança nos níveis regional e global.

Como marco temporal, o fim da Guerra Fria (1991) para o subcomplexo do Golfo foi datado a partir da Primeira Guerra do Golfo (1990-1). A derrota do Iraque em 1991 mudou algumas das estruturas básicas do subcomplexo do Golfo. Buzan e Wæver (2003) citaram quatro eventos que, após o fracasso da guerra para o Iraque, acabaram definindo as dinâmicas de segurança no Golfo no restante da década de 1990 e início do século XXI. Primeiro, o governo de Saddam Hussein passou a sofrer grande pressão interna e externa, ameaçando a unidade do país. A guerra foi seguida de insurreições tanto nos territórios de maioria curda, no norte, quanto nos de população majoritariamente árabe xiita, no sul - ambos brutalmente suprimidos pelo regime. A região, à época, quase autônoma do Curdistão também recebeu apoio externo, militar e político, do Irã, da Turquia e dos Estados Unidos (idem, 2003). Os curdos constituem o maior grupo étnico sem um Estado: são aproximadamente 25 milhões. Divididos entre Turquia, Síria, Irã e Iraque, têm sido reprimidos ou usados como espaço de manobra 
pelas rivalidades interestaduais. Assim, o Irã dá suporte à população curda no Iraque e vice-versa e a Síria apoia os curdos na Turquia (idem, 2003).

Segundo, a política dos Estados Unidos na região passou claramente para uma contenção dupla de Irã e Iraque. Estados Unidos e Israel incorporaram a suas políticas domésticas a hostilidade a ambos os países. Isso contribuiu para o maior entrelaçamento das dinâmicas de segurança entre os subcomplexos do Levante e do Golfo durante a década de 1990, enquanto o subcomplexo Maghreb passou a desconectar-se do núcleo principal (idem, 2003). Terceiro, o Iraque saiu da guerra enfraquecido militarmente, o que reforçou a posição do Irã na região. A neutralidade iraniana durante a guerra permitiu que o país fosse um dos principais beneficiados do conflito. Além de aumentar sua capacidade militar relativa na região, isso também o aproximou de seu rival regional (idem, 2003). As relações diplomáticas entre Bagdá e Teerã melhoraram devido às posições conjuntas contrárias ao papel intrusivo dos Estados Unidos no Oriente Médio e sua política de contenção dupla, bem como às negociações de paz entre Israel e a Organização para a Libertação da Palestina (OLP), em 1993. Ao passo que Irã e Iraque aproximaram-se, a rivalidade entre Irã e Arábia Saudita acirrou-se. Enquanto o CCG tornou-se ainda mais dependente da ajuda militar dos Estados Unidos, o Irã buscou pôr-se como um centro anti-Ocidente no CRSOM (idem, 2003).

Quarto, a Guerra do Golfo condicionou os Estados do CCG ao status de praticamente protetorados do Ocidente, particularmente dos Estados Unidos. As ameaças contínuas do Irã e do Iraque permitiram o alinhamento ao Ocidente com aval doméstico dos Estados do CCG. Depois da guerra, esses Estados, sobretudo Arábia Saudita e Kuait, realizaram grandes encomendas de armamentos aos Estados Unidos, à França e à Grã-Bretanha. A Arábia Saudita tornou-se um claro aliado na política de contenção dupla dos Estados Unidos contra Irã e Iraque (idem, 2003). Porém, o alinhamento dos Estados do CCG aos Estados Unidos teve seu preço: a perda de soberania, o que levou Buzan e Wæver (2003) a denominá-los protetorados, enquanto Nasser (2011) os classificou como Estados rentistas. Buzan e Wæver (2003) concluíram que os quatro eventos destacados, que se desenvolveram após a Primeira Guerra do Golfo, estão envolvidos em um quinto: a radicalização da rede Al-Qaeda como resposta à presença militar norte-americana na Arábia Saudita e no Oriente Médio como um todo. 


\section{Subcomplexo do Golfo Pérsico após Saddam Hussein}

Como foi exposto na seção anterior, o rebalanceamento da distribuição de poder no subcomplexo pôde ser percebido a partir dos eventos posteriores à Guerra do Golfo (1990-1), destacados a partir de quatro pontos por Buzan e Wæver (2003). Porém, a análise dos autores precede a retirada de Saddam Hussein do poder. Tendo em vista a tendência de enfraquecimento da estrutura básica triangular (Arábia Saudita, Irã e Iraque) do subcomplexo do Golfo, levanta-se a hipótese de que, a partir da invasão liderada pelos Estados Unidos, a disputa entre as potências regionais bipolarizou-se entre Irã e Arábia Saudita. A fim de analisar a hipótese proposta, primeiro esta seção explanará sobre a perda do status de potência regional do Iraque. Logo após, tendo em vista a queda de um dos polos da estrutura triangular, discorrerá acerca dos indicativos de realinhamento das parcerias estratégicas em torno da estrutura bipolar.

Neste momento, dar-se-á ênfase à deterioração das capacidades relativas do Iraque como potência regional tendo-se em vista, principalmente, as perdas geradas pela invasão liderada pelos Estados Unidos e a ascensão do Estado Islâmico após a retirada das tropas norte-americanas. Dois eventos que, na verdade, estão relacionados. Segundo a interpretação de Gause (2014), novas oportunidades foram apresentadas no início dos anos 2000 para o Irã. As invasões lideradas pelos Estados Unidos ao Afeganistão (2001) e ao Iraque (2003) abriram uma nova agenda política em dois vizinhos do Irã, sendo este último de maioria xiita. Foram retirados do poder dois regimes que mantinham padrões de inimizade com o Irã. A invasão do Iraque e a retirada do sunita Saddam Hussein do poder criaram novas condições para melhores relações nos setores políticos e econômicos entre Bagdá e Teerã. O Irã passou a ter relações razoavelmente próximas com o governo xiita iraquiano, conferindo incentivos econômicos e comerciais (FAHLANDER, 2011).

A retirada de Saddam Hussein do poder foi parte da política dos Estados Unidos do pós-ataque de 11 de setembro. Política que incluía também a reformulação econômica e política de países do Oriente Médio (idem, 2011).

A capacidade do Estado iraquiano tinha sido corroída severamente após a Guerra do Golfo, mas a invasão americana foi o golpe de misericórdia. Washington buscou derrubar os três principais pilares do regime autoritário proibiu o partido Ba'ath, dissolveu a força militar e expulsou da burocracia os 
quadros experientes que eram membros do partido -, em um esforço mal concebido para reconstruir o Estado. 0 que se seguiu foi uma abertura do sistema político iraquiano por influência política externa, mais notadamente do Irã (GAUSE, 2011, p. 10, tradução nossa).

0 enfraquecimento das capacidades do Iraque em relação às outras duas potências regionais do subcomplexo do Golfo após 1991 já havia sido apontado por Buzan e Wæver (2003) como indicativo de uma redistribuição de poder na estrutura básica triangular de rivalidade, o que se consolidou após a retirada de Saddam Hussein do poder. Há que se lembrar que o status de potência regional pressupõe influência e capacidades sobre os processos de securitização da região. Isso implica a possessão de capacidades políticas e militares, com suporte econômico para tais capacidades. Além dos fatores materiais, é preciso posicionar-se como potência regional, o que envolve comportamento (BUZAN; WÆVER, 2003).

0 Iraque perdeu quase todo seu armamento convencional durante a invasão liderada pelos EUA em 2003 (CORDESMAN; GOLD; BERNTSEN, 2014). Mesmo que os Estados Unidos desenvolvam uma grande parceria estratégica para o rearmamento do Iraque, é improvável que antes de 2020 consigam dar ao Iraque a força convencional de que ele necessita para dissuadir e defender-se contra o Irã (idem, 2014). Rearmar o Iraque também traz riscos para os Estados Unidos. Tendo-se em vista o crescente alinhamento entre os governos iraquiano e iraniano, pode haver compartilhamento de tecnologia militar, treinamento e inteligência entre os dois países. Assim, o material dos Estados Unidos transferido para o Iraque permitiria ao Irã acesso facilitado à tecnologia militar norte-americana (idem, 2014).

\section{Estado Islâmico}

No que se refere ao Estado Islâmico em seu intento de construir um Estado, ao passo que confronta o governo do Iraque, também busca tomar suas estruturas administrativas e o controle sobre o território, sobretudo nas zonas de maioria sunita. Conforme a organização consolida sua atuação em funções estatais, torna-se mais independente de financiamento externo, sustentando-se através da ampla gama de recursos presentes nos territórios iraquianos conquistados. 0 Estado Islâmico também tem se mostrado um ator não estatal, capaz de interferir nas dinâmicas regionais de segurança do Oriente Médio, entrelaçando ainda mais as dinâmicas dos subcomplexos 
centrais do CSROM: do Levante e do Golfo. Sua zona de controle atualmente atravessa os dois subcomplexos. A organização ocupa, desde 2014, um território contínuo e transnacional entre os Estados sírio e iraquiano.

A fase inicial do Estado Islâmico surgiu da cisão e radicalização do braço iraquiano do grupo sunita Al-Qaeda, a Al-Qaeda entre a Terra dos Dois Rios (2003 e 2006) (ROSINY, 2014), enquanto sua expansão em direção à Síria ocorreu em meio à guerra civil iniciada em 2011, fruto da contestação do regime de Bashar al-Assad no contexto da Primavera Árabe. As origens do Estado Islâmico remontam a 2003, quando a coalizão internacional liderada pelos Estados Unidos invadiu o Iraque e derrubou o regime sunita de Saddam Hussein, no poder desde 1979. Valendo-se da animosidade contra a presença norte-americana no Iraque e do descontentamento da população sunita, que passou a ser negligenciada pelo governo, em 2006, a Al-Qaeda entre a Terra dos Dois Rios buscou expandir suas operações e autoproclamou-se Estado Islâmico do Iraque. A partir de então, passou a buscar uma "evolução qualitativa de um grupo insurgente para transformar-se em um ator político-militar responsável por governar um território" (LISTER, 2014, p. 9, tradução nossa).

O Estado Islâmico, em agosto de 2014, abrangia entre 25\% e 30\% das áreas povoadas do território iraquiano, o que significa aproximadamente $13 \mathrm{mil}$ a $17 \mathrm{mil}$ quilômetros quadrados (ESTADOS UNIDOS DA AMÉRICA, 2015). Em "um contexto amplo de instabilidade e conflito, a combinação do Estado Islâmico de lei rígida e de repressão com a provisão de serviços essenciais e assistência tem, por vezes, levado a uma aceitação tácita em nível local" (LISTER, 2014, p. 2, tradução nossa). Ademais, a organização faz uso de atentados com carros-bomba e homens-bomba, sequestros e ataques a postos de comando dos governos da Síria e do Iraque e a civis. Esses atos têm o objetivo de minar a confiança da população na capacidade dos Estados sírio e iraquiano de prover segurança e outros serviços públicos, ao passo que o próprio Estado Islâmico apresenta-se como protetor (idem, 2014). Os territórios dominados constituem zonas de maioria árabe sunita, o que denota também a ascensão do uso das divisões sectárias e étnicas para determinar padrões de amizade e inimizade. Nessas áreas, a organização apresenta a capacidade de assegurar grandes quantidades de recursos de fontes internas de modo independente de fundos internacionais, ainda que as doações externas sejam significativas (HUMUD; PIROG; ROSEN, 2015). Controla, ainda, uma 
variedade de recursos públicos e de infraestrutura em partes do Iraque e da Síria, permitindo o acesso a um leque diverso de fontes de financiamento. Alguns desses recursos, tais como petróleo e antiguidades, podem ser contrabandeados e vendidos com grande margem de lucro. Outros - como produtos agrícolas, água e energia -, ao passo que requerem grande capacidade técnica e investimentos, geram pouco lucro. Porém, a manutenção da produção e distribuição desses recursos tem papel importante na legitimação da autoridade sobre a população. Também são desenvolvidas atividades rentáveis, porém não sustentáveis a longo prazo, como assaltos a bancos estatais no Iraque e sequestro em troca de resgate. Do controle do conjunto geral desses recursos são notáveis não somente as receitas arrecadadas, mas também a limitação da capacidade dos governos sírio e iraquiano em realizar comércio, prestar serviços e promover a segurança alimentar da população, funções as quais o Estado Islâmico acaba transferindo para si (idem, 2015).

No Iraque, o Estado Islâmico enfrenta, sobretudo, os enclaves das forças de segurança iraquianas junto às milícias xiitas no leste e a pershmerga curda no norte do país (CODERSMAN, 2014). Tanto as forças armadas iraquianas quanto os curdos são apoiadas com armamentos e treinamento norte-americanos. Porém, Bagdá exige que o auxílio à pershmerga passe por seu aval, pois teme que o fortalecimento militar dos curdos possa reforçar a reivindicação pela independência da Região Autônoma do Curdistão uma vez que o inimigo comum, o Estado Islâmico, seja eliminado (KATZMAN et al., 2015). 0 aumento das tensões sectárias e étnicas já havia sido apontado por Buzan e Wæver (2003) no período pós-Guerra do Golfo (1990-1). Com a saída de Saddam Hussein, essas tensões exacerbaram-se.

Em 2014, o então primeiro-ministro iraquiano Maliki foi sucedido por Haidar alAbadi, que assumiu o cargo com a missão de evitar a desintegração do país, em boa medida fomentada por seu antecessor. Em abril de 2015, Abadi viajou a Erbil, capital da Região Autônoma do Curdistão, a fim de negociar a junção das operações militares contra o Estado Islâmico. Desde agosto de 2014, os Estados Unidos têm realizado ataques aéreos em território sírio e iraquiano contra alvos do Estado Islâmico, porém, até então, havia descartado o retorno das tropas americanas ao Iraque (HUMUD; PIROG; ROSEN, 2015). O Iraque, de uma potência regional enfraquecida pós-Guerra do Golfo em 1991, teve suas capacidades reduzidas pelos eventos que se seguiram - destaque para a 
invasão e a ocupação iniciadas em 2003, atreladas ao surgimento e à ascensão do Estado Islâmico - de tal maneira que hoje corre o risco de perder sua unidade territorial.

\section{Mudança nos padrões de amizade e inimizade}

A mudança de polaridade no interior do subcomplexo pode também ser apreendida pela transformação nos padrões de amizade e inimizade entre os Estados que o compõem. Haja vista que a TCRS também tem raízes no construtivismo, a formação e a operação dos CRSs seguem padrões de amizade e inimizade entre as unidades do sistema, o que torna os Estados dependentes das ações e das interpretações dos atores, não somente o mecanismo de reflexão da distribuição de poder (BUZAN; WÆVER, 2003). No subcomplexo do Golfo, a revolução no Irã em 1979 adicionou um elemento ideológico à sua rivalidade com a Arábia Saudita. Desde então, ambos os Estados reivindicam a liderança de universalismos islâmicos oponentes: sunismo e xiismo (idem, 2003). Pós-Saddam Hussein, o elemento sectário ganhou peso ainda maior, não só internamente no Iraque, mas em todo o subcomplexo do Golfo. 0 sectarismo entre sunitas e xiitas tem papel importante na construção dos padrões de amizade e inimizade no Golfo Pérsico, na disputa entre Arábia Saudita e Irã (GAUSE, 2014). Porém, uma simples dicotomia entre xiitas e sunitas é simplista. Embora domesticamente Arábia Saudita (sunita-Wahhabi) e Irã (xiita) sustentem regimes sectários, isso não significa que sua política externa é guiada por motivos religiosos. Riad e Teerã cruzam a linha sectária para angariar aliados regionais (idem, 2014). As potências regionais, Irã e Arábia Saudita, precisam dessas relações ideológicas ou identitárias para consolidar seus alinhamentos com os governos ou grupos domésticos em países vizinhos (idem, 2014).

Esse antagonismo desempenha um papel importante para o Irã em suas relações com os países árabes mulçumanos, onde procura se projetar como centro entre os mulçumanos xiitas. Assim, a religião é usada como fator de união e divisão (FAHLANDER, 2011, p. 16). Para o Irã (persa), qualquer disputa com um vizinho árabe no CRSOM pode ser interpretada como uma contenda contra todos os países árabes, como fica evidente no caso de Israel (judeu), enquanto as monarquias árabes do Golfo não traduzem seus enormes ingressos da venda de petróleo em suporte a movimentos islâmicos com apoio popular e, pelo contrário, tornam-se mais dependentes dos 
interesses ocidentais na região, acabam sendo vistas como traidoras antiárabes, antiislâmicas e pró-Israel (BUZAN; WÆVER, 2003). Assim, enquanto o pan-islamismo e o pan-arabismo são ideias que não conseguiram suplantar ou ameaçar sistema estatal vestfaliano no Oriente Médio, por outro lado afetam poderosamente o modo como esse sistema de estados é operado. Os níveis nacionais e regionais também atuam um no outro com governos apoiando as facções domésticas em outros estados: Líbia e Irã pós1979 apoiando movimentos radicais, e a Arábia Saudita, movimentos conservadores e islâmicos. No Golfo, muitos grupos xiitas locais mantêm ligações com o Irã (idem, 2003). Fora do subcomplexo do Golfo, o Irã sustenta alianças de longa data com o Hezbollah no Líbano e com o governo de Bashar al-Assad na Síria.

Com a perda, por parte do Iraque, do status de potência regional e com o Egito ex-rival da Arábia Saudita na disputa pela liderança da comunidade pan-árabica - preso atualmente à instabilidade interna após a Primavera Árabe, os conflitos entre as potências regionais árabes parecem ter cessado ou logrado uma trégua (FAHLANDER, 2011). Já no que diz respeito às relações entre as potências regionais islâmicas, houve o acirramento da bipolaridade entre Irã e Arábia Saudita, ou CCG de modo mais abrangente. Ambos tentam reivindicar legitimidade para representar uma comunidade muçulmana mais ampla, para além do subcomplexo do Golfo. Seu poder de equilíbrio mútuo baseia-se na construção de padrões de amizade e inimizade com vista na religião, bem como ligações étnicas, em que os estados vizinhos estão, em geral, alinhados adequadamente (idem, 2011).

No que se refere à balança militar no subcomplexo, nota-se que o Irã não tem modernizado seus armamentos a uma taxa semelhante à dos Estados do CCG (CORDESMAN; GOLD; BERNTSEN, 2014). O Irã busca aprimorar suas forças convencionais de modo a expandir sua influência, limitar as opções militares dos Estados Unidos e aumentar suas capacidades de dissuasão de seus vizinhos e de projeção de poder (idem, 2014). A potência regional, a fim de responder às limitações de suas forças convencionais, tem se destacado pelo desenvolvimento de forças irregulares e não convencionais para proteção de seu território contra invasões.

Quanto ao outro polo da estrutura bipolar do subcomplexo do Golfo, cada Estado-membro do CCG tem, bilateralmente, alinhamento aos Estados Unidos para garantir proteção política, militar e econômica para assegurar a sobrevivência de seus 
Estados artificialmente criados, sempre questionados pelo mesmo ideal pan-arabista que dá legitimidade aos seus regimes e sustentação ao CCG, o Conselho de Cooperação dos Estados Árabes do Golfo. Não obstante, a situação que se apresenta hoje é a de assegurar a sobrevivência dos regimes por meio do alinhamento compulsório aos Estados Unidos, o que, invariavelmente, confronta o ideal nacionalista árabe de libertação de toda forma de ingerência externa (FARABOLLI, 2007). A problemática envolvida nessa situação vem gradualmente revelando-se pela proliferação de grupos e organizações ditos islâmicos - nunca pan-arabistas - que cometem atentados contra os Estados árabes mais explicitamente atrelados ao Ocidente e contra a própria superpotência. 0 fundamentalismo islâmico, tal como o sustentado pelo Estado Islâmico, vem como um questionador das autoridades árabes (idem, 2007).

Em face da institucionalização do CCG, mesmo que tímida, o Irã tem buscado aliados estratégicos no CRSOM. Tendo-se em vista as escassas opções de parcerias estratégicas no subcomplexo do Golfo - dada a abrangência da CCG -, o Irã buscou aproximar-se do Iraque. Também fornece apoio ao Hezbollah no Líbano e aos xiitas no Bahrein, além da longa parceria com Assad e os alauitas na Síria. Fahlander (2011) aponta que o Irã tem buscado parcerias inter-regionais para balancear a aproximação do CCG ao Ocidente, especialmente aos Estados Unidos. Antes do final da Guerra Fria, a União Soviética era o parceiro natural para equilibrar a influência dos Estados Unidos na região. Mas, desde a desintegração do bloco soviético, o Irã buscou contrapor a influência dos EUA por meio da participação no Movimento dos Não Alinhados e na Organização dos Países Exportadores de Petróleo (Opep). Também logrou o status de país observador na Liga Árabe e no Conselho de Cooperação de Xangai (OCX). Porém, essas iniciativas têm pouco impacto, especialmente no setor de segurança. A maioria tem baixo grau de institucionalização e não ultrapassa o setor econômico.

Como exposto, a polaridade do subcomplexo do Golfo, após a perda de status do Iraque como potência regional, passou de triangular para bipolar. Essa mudança de polaridade também afeta os padrões de amizade e inimizade na região, de modo que, como observou Fahlander (2011), outros Estados do subcomplexo precisam encaixar-se na bipolaridade entre Irã e Arábia Saudita, o que, no futuro, implicará um posicionamento do Iraque entre os polos. Parece que o Irã tem tomado vantagem em aproximar-se do Iraque, ao passo que aumenta suas relações no setor econômico e 
explora a exacerbação dos padrões de amizade e inimizade em torno das divisões sectárias para alinhar-se ao governo xiita iraquiano.

\section{CONSIDERAÇÕES FINAIS}

Como apontado por Buzan e Wæver ainda em 2003, antes mesmo da retirada de Saddam Hussein do poder, o subcomplexo do Golfo estava alicerçado em uma estrutura triangular básica de rivalidade já com sinais de mudança de polaridade. A mudança da polaridade confirmou-se após a invasão e a ocupação lideradas pelos Estados Unidos (2003-2011). Os eventos abriram espaço para o surgimento e a ascensão do Estado Islâmico nos territórios iraquianos de maioria sunita. Após a retirada das tropas norteamericanas do Iraque (2011), o país enfrenta graves desafios para a manutenção da unidade de seu território em face do armamento da Região Autônoma do Curdistão ao norte e do controle, pelo Estado Islâmico, de aproximadamente um quarto do território iraquiano. A perda das capacidades do Iraque diante dos eventos que se seguiram à queda de Saddam Hussein inviabilizou a manutenção de seu status de potência regional.

Perante a queda de uma potência regional, sendo esta responsável pela definiçãa da polaridade do subcomplexo, é natural que a polaridade ajustar-se-ia entre as outras duas potências regionais, bipolarizando-se entre Irã e CCG. O Irã parece ter sido o maior beneficiado da queda do Iraque, pois, além do ganho de capacidades militares relativas e da retirada de um governo hostil, também pôde aproximar-se do governo do xiita Maliki em um contexto de agravamento das tensões étnicas e sectárias na região.

Assim, a bipolarização também tem dado indícios de transformações nos padrões de amizade e inimizade no subcomplexo do Golfo. Ao passo que Irã e Iraque aproximaram-se, a rivalidade entre Irã e Arábia Saudita acirrou-se. Enquanto o CCG tornou-se ainda mais dependente, nos setores militar, econômico e político, em relação aos Estados Unidos, através de mecanismos de penetração da superpotência na região, o Irã buscou pôr-se como um centro anti-Ocidente no CRSOM entre os mulçumanos, sobretudo xiitas. Assim, a religião é usada como fator de união e divisão.

A rivalidade entre Arábia Saudita e Irã transfere-se também para o nível doméstico dos Estados que compõem os subcomplexos do Golfo e do Levante. $\mathrm{O}$ apoio a 
entidades subestatais e grupos armados rivais, geralmente seguindo divisões sectárias, porém, não é uma regra. Tendo-se em vista a escassez de possíveis parcerias estratégicas com Estados do subcomplexo do Golfo, o Irã tem buscado projetar sua influência não só no CRSOM, mas também em relações de nível inter-regional, embora ainda muito tímidas. 0 futuro do desenvolvimento do programa nuclear iraniano talvez forneça mais indícios sobre a redefinição dos alinhamentos estratégicos no Golfo e no CRSOM, o que também envolverá o posicionamento do Iraque nessa nova estrutura bipolar no subcomplexo.

\section{REFERÊNCIAS}

BUZAN, Barry.; WAEVER, Ole. Regions and powers: the structure of international security. Cambridge: Cambridge University Press, 2003.

CORDESMAN, Anthony. H.; GOLD, Bryan; BERNTSEN, Garrett. The Gulf Military Balance. Volume I: The Conventional and Asymmetric Dimensions. Center for Strategic \& International Studies. Washington, 2014.

ESTADOS UNIDOS DA AMÉRICA. Lead Inspector General for Overseas Contingency Operations: Operation Inherent Resolve. Quarterly Report and Biannual Report to United State Congress. Washington, Departamento de Defesa dos Estados Unidos, 17 dez. 2014 - 31 mar. 2015.

FAHLANDER, Patric. Regional security in the Persian Gulf: indications of change in a Regional Security Complex. Lunds: Lunds Universitet Statsvetenskapliga Institutionen, STVM01, VT11, 2011.

GAUSE, Beyond sectarianism: the new Middle East Cold War. Brookings Doha Center Analysis Paper. Doha, n. 14, jul. 2014

HUMUD, Carla; PIROG, Robert; ROSEN, Liana. Islamic State Financing and U.S. Policy Approaches. Congressional Research Service, [l.n], CRS Report, 10 abril 2015.

KATZMAN, Kenneth et al. The "Islamic State" Crisis and U.S. Policy. Congressional Research Service, [l.n], CRS Report, 11 fev. 2015.

LISTER, Charles. Profiling the Islamic State. Brookings Doha Center Analysis Paper. Doha, n. 13, nov. 2014.

NASSER, Reginaldo. Turbulências no Mundo Árabe: rumo a uma nova ordem? Revista Tempo do Mundo. Brasília, v.3, n.2, p. 141-170, 2011.

ROSINY, Stephan. The Caliph's New Clothes: The Islamic State in Iraq and Syria. Focus - German Institute of Global and Area Studies, Hamburgo, n. 6, 2014. 